\title{
Medflow Architecture for Online Medicine
}

\author{
Akshay Gale ${ }^{1 *}$, Mayur Waghmare ${ }^{2}$, Aarti Ragella ${ }^{3}$, Rohan Swashinkar ${ }^{4}$, Vishal Sontakke , $^{5}$ \\ Aarti M. Ragella ${ }^{6}$ \\ 1,2,3,4,5Student, Dept. of Information Technology, Bapurao Deshmukh College of Engineering, Wardha, India \\ ${ }^{6}$ Assistant Professor, Department of Information Technology, Bapurao Deshmukh College of Engineering, \\ Wardha, India \\ *Corresponding author: akshaygale19@gmail.com
}

\begin{abstract}
Applications like NETMEDS have a fundamental drawback that users don't know from where the medicines are being delivered. It has been one of the most challenging part for several people to order medicine online. In day-to-day world, if we visit medical shop then we get the proper medicine i.e., fresh to consume and extracted from a trusted source. In the proposed system, we have created a web portal that will help the customer to order medicine and going to help the vendor for maintaining stock availability online.

The prime focus was to order medicine from a trusted source online and to deliver the medicine from trusted source. A web portal is created to order medicine from trusted sources and from specific area. We are going to select the vendor by ourselves and we're going to add the online payment portal, a map link and a discount section to buy medicine. This is going to be carried out using Java 7, Java Server faces J2EE, Bootstrap 4 and Tomcat 7 in order to make our portal interactive.

The web portal is almost created, we are able to search for areas and input the medicine stock from vender's side, the map link to the vender's shop, online payment portal with a search and filter ability. The existing systems requests for the prescriptions and the source of the medicine stores and sellers are not provided. To stay away from such framework, we have created a web application that can connect the customers as well as the nearby vendors. As the clients trust on close by drug store owners, so we have proposed a structure where client will have the option to look through medication's accessibility in close by shop. Additionally, they will have the option to check accessibility for prescriptions. As the seller will be realized client will be agreeable for requesting prescription. In addition to that, we are giving online payment portal.
\end{abstract}

Keywords: Medflow, Online medicine, Online pharmacy.

\section{Introduction}

Applications like NETMEDS have a principal downside that clients don't know from where the drugs are being conveyed. Because of this client waver to request meds regardless of whether high limits are given. Likewise, simultaneously therapeutic drug store and merchants caution individuals about expiry conveyance and different perils [1].

To maintain a strategic distance from such framework and to profit the neighborhood sellers we can structure a framework that can give clients nearby prescriptions conveyance. This will take care of two noteworthy issues. First the conveyance will draw near single day and second clients can know from where the medications are coming. Because of this clients and sellers both will be profited. Likewise, the clients will be furnished with subtleties where the prescription is accessible. Because of wellbeing safety measure $98 \%$ of populace still purchase meds from close-by drug store and don't organization it on the web [2].

The primary explanation for it is the client doesn't know from where the prescription is conveyed and furthermore the procedure isn't that simple. We are proposing a system where client will most likely hunt medications accessibility in closeby shops to him dependent on city. Additionally, they will almost certainly check markdown accessibility and minimal effort accessibility for meds. As the merchant will be realized client will be agreeable for requesting drug [3]

To provide computerized data storage facility. We can search easily any record. The new system requires less time for completion of any work. All the stock of medicine is update automatically in the new system. The system is user friendly and anyone having computer knowledge can handle it easily. Suitability for computerized data entry. Maintaining stock, supplier information, customer information and bill information are easy. An online pharmacy, internet pharmacy, or mail-order pharmacy is a pharmacy that operates over the Internet and sends orders to customers through mail, shipping companies, or online pharmacy web portal.

\section{A. Online pharmacies include}

Pharmacy benefits managers: Entities that administrate corporate prescription drug plans. Legitimate Internet pharmacies in the same country as the person ordering.

Legitimate Internet pharmacies in a different country than the person ordering.

This type of pharmacy is usually licensed by its home country and follows those regulations, not those of the international orders.

Illegal or unethical internet pharmacies. The web page for an illegal pharmacy may contain lies about its home country, procedures, or certifications.

The "pharmacy" may send outdated (expired shelf life) or counterfeit medications and may not follow standard procedural 
safeguards.

An online pharmacy is a pharmacy that operates on the Internet to sell medications to consumers. There are online pharmacies in many countries of the world-from India, the U.S., Germany, the UK-and many other nations that sell to consumers in their own countries and often to consumers worldwide [6].

Depending on its location and local regulations, an online pharmacy may or may not require prescriptions to purchase prescription medications.

Prices at a given online pharmacy can vary from one city or country to another. Typically, drug prices at online pharmacies located in countries with drug price controls in place (i.e., India, UK, Germany, South Africa) will have more affordable costs.

In contrast, costs at pharmacies in countries where there are no drug price controls (i.e., U.S.) will usually be much higher. Especially for consumers seeking low-priced medications, it can be very worthwhile to compare prices at various online pharmacies. Prices can vary as much as 80 percent or more for one medication from one country to another [8].

\section{B. Medflow}

Online medicine shopping is a form of electronic shopping store where the buyer is directly online to the seller's computer usually via the internet. There is no intermediary service. The sales and purchases transaction is completed electronically and interactively in real-time. The development of this new system contains the activities which try to develop on-line application by keeping the entire process in the view of database integration approach.

\section{Scope of online medicine in India}

Online pharmacy model is getting more and more attention of investors and entrepreneurs. According to industry experts, this sector has great business potential and is believed to grow from $\$ 18$ billion markets to $\$ 55$ billion by 2020 .

Since Pharmacy is a healthcare sector, it comes with its own rules and norms which are to be followed strictly to ensure the quality and safety of drugs as well as human lives. When I first heard about this new concept of online purchasing of drugs,

The number cannot be exactly estimated, however, based on a search, around 3000 online pharmacies were found, and half of them were based in the USA and $19 \%$ in UK and the balance in other countries like India, Canada, etc. In another finding, B2-B companies also offered online pharmaceuticals of which $19 \%$ are from India.

\section{Literature Review}

Alamelu R, et al [1] proposed that Online pharma retail is promising/ unpromising avenue: In this era of science and technology, computer plays an important role in community. Today, computer is so ubiquitous in pharmaceutical research and development. The advent of the internet has had a significant impact on the formation of an information-driven, rapid-paced society. The number of internet users reached 150 million in only five years compared to 13 years for television and 38 years for radio. Consumer expectation for access, convenience, and speed has made the cyberspace superhighway a medium for knowledge exchange and for e-commerce. The internet offers a wide variety of health services and products to healthcare professionals as well as to the public. Online pharmaceutical sales have reached more than nearly $\$ 50$ billion. This is a dramatic increase when compared to the $\$ 1.9$ billion in 1999. At the click of the mouse, medications can be ordered and delivered conveniently to your door. Internet has evolved into a self-organizing media, capable of multiple interactions within [1].

Anand, A., Sethi, et al [2] proposed a large number of consumer products including drugs are being advertised and sold over the Internet. Though the marketing of drugs over the Internet is an inevitable outcome of the booming e-economy, it poses unique ethical, legal and quality challenges- the prime cause being the anarchic structure of the Internet. These challenges are important from the consumer, physician and regulator perspectives. This paper begins with a summary of historical considerations and the shifting organization of internet pharmacy. The advantages and disadvantages of internet pharmacy practice are listed. Internet pharmacy is not only affordable but also can be source of easy availability of medicine [2].

George C, et al [3] proposed that, in both jurisdictions, regulators have issued guidelines to address the practice of issuing prescriptions online. This practice is not seen as consistent with good medical care and is not encouraged in either jurisdiction. There are however, subtle differences in the scope of regulation of this practice for each jurisdiction. The UK has taken a more relaxed attitude to this issue (compared to the US), although there has been one case of suspension of a doctor for conduct related to prescribing online. In the UK Medical guidance given by the GMC does not expressly prohibit remote (online, email, telephone, video link) prescribing but instead gives doctors guidelines according to particular circumstances. Specific guidelines are given where the doctor: has responsibility for the patient; is deputizing for the patient's doctor; or has prior knowledge and understanding of the patient's condition(s)/medical history, and is authorized to access the patient's records [3].

Jain V. H, et al [4] proposed a review on the pros and cons of online pharmacies. Buying medicines online is common practice across the globe these days. This is because buyers are preferring to order for medicines through a click of a button rather than taking a trip to a drug store. Such online websites sell everything from prescription drugs to health related products. Most of such stores are legal outlets that safeguard all traditional procedures related to drug prescription. That is why most buyers are confident about dealing with these stores. But there are quite a few rogue stores that have come up in the recent past over the internet. These stores deal in illegal medications and unapproved drugs, buyers must be aware of 
such rogue stores. The DEA department will also helping the nation. The fact remains that drugs purchased at online drug stores offer high levels of handiness, put forward privacy for the buyer as well as safeguard traditional procedures of prescribing drugs [4].

A. Didar, et al [5], prefer to access both domestic and global products at the click of a button, and at competitive prices. This also extends to the rural consumers who have a rising economic status with better access to the Internet. From a long-term perspective, this change in the consumer behavior is expected to benefit the country's economy as well. On the contrary, there is a lot of debate around the e-Commerce industry impacting brick and mortar retailers and SMEs. The current battle by the retailers against e-Commerce is similar to the scenario during the industrial revolution. There was a threat posed against machines replacing man power and impacting the economy of the country; however, in reality, the industrial revolution created a massive demand for labor. Similarly, when organized retail stores as well as online shopping sites came into the market, there were similar concerns raised around them being a threat to local traders, corner stores, and retailers. However, it has been repeatedly observed that newer models have only led to market creation; thus, leading to sufficient space for coexistence [5].

Jacobian E, et al., [6] proposed, advantages and disadvantages of buying medicines though online pharmacy. Due to health precaution $98 \%$ of population still buy medicines from nearby pharmacy and don't order it online. The main reason behind it is the user doesn't know from where the medicine is delivered and also the process is not that easy. Anyone can upload fake prescription and will misuse it [6].

\section{Proposed Work}

\section{A. Algorithm}

Step 1: Start and login (customer).

Step 2: Read Medicine name from user.

Step 3: Using DB Search, find all the stores having the same medicine.

Step 4: Using Filter F, from user filter the results in three different sections
a. Cost based filtering
b. Rating based filtering
c. Availability Filtering

Step 5: Return updated results to user.

Step 6: Make online payment or cash on delivery.

Step 6: Exit

\section{B. Design and calculation}

The main motivation behind the web developers and administrators is to design a robust web system that should reflect their working strategies as a skilled networking engineer and as an efficient web developer. The important Here we are using separate module design for the admin, vendor and for the customer.
Here we are using the different design phases for designing the required module which provided the benefit to all the users and the vendors. Here in this module the gather information will shown on the screen as well as the database. The customer can easily search and identified the required name of the medicine and their availability in the nearest medical shops.

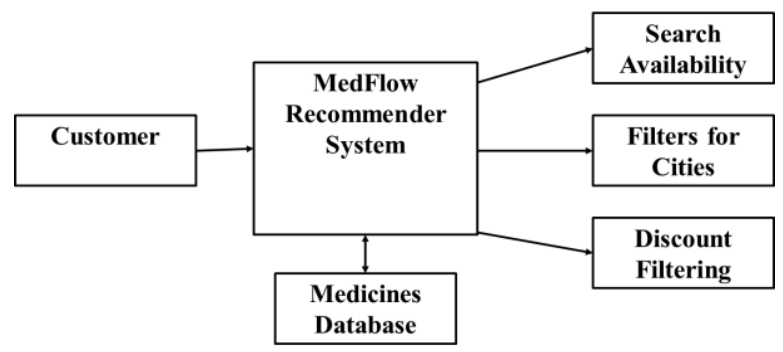

Fig. 1. System architecture of proposed system

The rate of medicine will vary in the different medical, all the information will shown to the customer on the website. This will help the customer to make decision to get the perfect medicine. The system Architecture of proposed system will work with some properties which will applied in design and how the proposed work will have done that are follows:

In proposed work, we will be providing role based logins for admin and vendors. Vendors will be able to update their stock of medicines online.

Customers can make a direct search on medicines based on availability in locations. Also customer will be able to view discounts and other schemes provided by vendors. The database will provide all the required information of the medicine where the customer needed.

\section{Design phases}

The design of the project is divided into the three phase i.e. Search Engine, Module Filtering, Admin. Search Engine module is used for the customer, filtering is used to filter among the cost, rate and location and the phase three is for the admin.

\section{Feasibility study}

A feasibility analysis involves a detailed assessment of the need, value and practicality of a proposed enterprise, such as systems development. The process of designing and implementing record keeping systems has significant accountability and resource implications for an organization. Feasibility analysis will help you make informed and transparent decisions at crucial points during the developmental process to determine whether it is operationally, economically and technically realistic to proceed with a particular course of action. Most feasibility studies are distinguished for both users and analysts. First, the study often presupposes that when the feasibility document is being prepared, the analyst is in a position to evaluate solutions. Second, most studies tend to overlook the confusion inherent in system development - the constraints and the assumed attitudes. 


\section{E. Operational feasibility}

People are inherently resistant to change, and computers have been known to facilitate change. An estimate should be made of how strong a reaction the user staff is likely to have toward the development of a computerized system. It is common knowledge that computer installations have something to do with turnover, transfers, retraining, and changes in employee job status. Therefore, it is understood that the introduction of a candidate system requires special effort to educate, sell and train the staff on new ways of conducting business.

\section{F. Technical feasibility}

Technical feasibility centers around the existing computer system (hardware, software, etc.) and to what extend it can support the proposed addition. For example, if the current computer is operating at 80 percent capacity - an arbitrary ceiling - then running another application could overload the system or require additional hardware. This involves financial considerations to accommodate technical enhancements. If the budget is a serious constraint, then the project is judged not feasible.

\section{G. Cost/Benefit analysis}

Economic analysis is the most frequently used method for evaluating the effectiveness of a candidate system. More commonly known as cost benefit analysis, the procedure is to determine the benefits and savings that are expected from a candidate system and compare them with costs [7]. If benefits overweigh costs, then the decision is made to design and implement the system. Otherwise, further justification or alterations in the proposed system will have to be made if it is to have a chance of being approved. This is an ongoing effort that improves in accuracy at each phase in the system life cycle.

\section{H. Objectives}

- To develop a web application using J2EE.

- Provide role based login for admin and shop owners.

- Provide search engine for customers to search for medicine in nearby areas.

\section{Conclusion}

The existing systems requests for the prescriptions and the source of the medicine stores and sellers are not provided. To stay away from such framework, we have created a web application that can connect the customers as well as the nearby vendors. As the clients trust on close by drug store owners, so we have proposed a structure where client will have the option to look through medications accessibility in close by shop.

Additionally, they will have the option to check accessibility for prescriptions. As the seller will be realized client will be agreeable for requesting prescription. In addition to that, we are giving online payment portal as well as we will be giving a separate discount portal.

\section{Future Scope}

In the future, it will help the people who didn't get the time to bring the medicine at home due to some reasons. So, it will help needy people who want the medicine at the door. And someone having trusted issue they can also trust on our website portal to get the medicine.

\section{References}

[1] Alamelu R., Amudha R, Motha, L.C.S., \& Nalini R, (2016). Online pharma retail is promising/ unpromising avenue: An Indian context. Asian journal of pharmaceutical and clinical research, $9(2)$.

[2] Anand, A., Sethi, N., Sharon, G. (2010). Internet pharmacy: Need to be implemented in India. Chronicles of young scientists, 1(1), 16-25.

[3] George C. (2009). Internet Pharmacies: Global threat requires a global approach to regulation. Telehealth Law, 9(3).

[4] Jain, V. H., Tadvi, S.A. and Pawar, S. P. (2017). A review on the pros and cons of online pharmacies. Journal of Applied Pharmaceutical Research5 (1): 20-26

[5] http://ficci.in/spdocument/20746/E-Pharmacy-in-India-Last-MileAccess-to-Medicines_v5.pdf

[6] Jacobian E, Advantages and Disadvantages of Buying medicines though online pharmacy. Pharma Science, 11, 2014.

[7] Gruzd, A. Wellman, B. S., and Takhteyev, Y. (2011), Imagining Twitter as an imagined community. American Behavioral Scientist, 55(10) pp. 1294-1318.

[8] Kevin C., Graham S., and Temple C, (2011), Advertising on Facebook. International Journal of E-Business Development, 1: 26-33

[9] Lu Y, Zhao L, and Wang B, (2010), From virtual community members to c2c e-commerce buyers: trust in virtual communities and its effect on consumers' purchase intention. Electronic Commerce Research \& Applications, 9(4), pp. 346-360. 